\title{
Pengembangan Aplikasi E-Learning Berbasis Semantic Web Pada Balai Tekkom Dinas Pendidikan Provinsi Banten
}

\author{
Yani Sugiyani ${ }^{1}$, Roy Amrullah Ritonga ${ }^{2}$, Jamjuri $^{3}$ \\ Program Studi Sistem Informasi, Fakultas Teknologi Informasi - Universitas Serang Raya \\ Jl Raya Serang - Cilegon, KM 5 Taman Drangong, Kota Serang - Banten, Indonesia \\ Yani.Sugiyani@Gmail.com, \\ Roy.Amrullah@Gmail.com, \\ Jamjuri80@Gmail.com
}

Abstrak, Teknologi informasi memberi kemudahan bagi siapa saja untuk mendapatkan informasi.Sekolah sebagai tempat belajar menjadi tempat yang tepat untuk penerapan teknologi informasi.Jarak kini tak lagi menjadi kendala untuk belajar.Teknologi Informasi menjadi media bagi seluruh komponen sekolah untuk mendapatkan informasi.

Balai Tekkom Dinas Pendidikan Propinsi Banten membuat sistem informasi sekolah (E-Learning) berbasis web yang diberi nama Pusat Sumber Belajar. Sistem ini diharapkan menjadi sarana sekolah untuk berbagi informasi ke seluruh komponen sekolah.Kepala sekolah dapat menginformasikan program-program sekolah. Guru dapat memberikan materi pelajaran . Murid dapat mengakses bahan pelajaran dan informasi mengenai kegiatan sekolah .Orang tua dan pihak luar dapat memantau kegiatan sekolah, semua secara online.

Pusat Sumber belajar nantinya akan diterapkan diseluruh sekolah di wilayah Propinsi Banten. Harapan kedepannya agar PSB dapat menjadi sumber informasi tidak hanya sebatas komponen di sekolah masing-masing tapi juga bagi siapapun yang berkeinginan mendapatkan bahan ajar dan informasi tentang sekolah.

Kata Kunci : E-Learning, Pusat Sumber Belajar, Balai Tekkom, informasi, guru, Sekolah

\section{LATAR BELAKANG}

Perkembangan ilmu pengetahuan dan teknologi dalam era globalisasi ini terjadi dengan sangat cepat. Kemampuan sebuah organisasi dalam mengaplikasikan ilmu dan teknologi menjadi salah satu faktor daya saing yang sangat penting. Saat sebuah organisasi mencoba mengembangkan kinerjanya, maka dibutuhkan tingkat pengetahuan yang sangat luas pada setiap personil yang ada untuk dapat berkompetisi dan bertahan. Kondisi kompetisi yang semakin ketat menyebabkan perlu adanya perubahan paradigma dari resource-based competitiveness menjadi mengandalkan knowledge-based competitiveness. Kedua konsep ini sangat bertolak belakang, dimana konsep pertama bertumpu pada keunggulan sumber daya alam lokasi dan 
kondisi geografis. Konsep kedua berdasarkan pada ilmu pengetahuan dan teknologi (IpTek) serta pengembangan sumber daya manusia perusahaan diperlukan kemampuan untuk mengelola dan mengembangan knowledge yang dimilikinya. Pengelolaan knowledge (Knowledge Management) tersebut pada akhirnya dapat menjadi dukungan yang handal bagi organisasi untuk mengembangan daya saing.

Pengelolaan Knowledge dapat menggunakan Teknologi Informasi dan Komunikasi (TIK), namun penggunaan TIK untuk mengelola knowledge bukannya tanpa masalah. Griffith et al menemukan bahwa dengan implementasi TIK dalam Knowledge Management System bisa menimbulkan dampak yang sifatnya sosial dalam organisasi bersangkutan. Misalnya, sebelum implementasi TIK dalam proses transfer knowledge, pemilik asal knowledge (knower) adalah individu yang unik. Setiap kali ada individu lain yang membutuhkan knowledge yang hanya diketahui oleh knower tadi, maka ia harus bertemu langsung dan menanyakannya kepada knower tersebut. Dengan diimplementasikannya TIK dalam proses knowledge management, knower tadi bisa merasa kehilangan keunikannya karena semua knowledge yang diketahuinya harus diserahkan ke sistem untuk diketahui semua orang. Sehingga sebagian orang merasa enggan untuk berbagi knowledge-nya.

Selain itu, alasan lain guru-guru enggan berbagi knowledge, dikarenakan sulit dan memerlukan waktu untuk merumuskan pengetahuannya dalam bentuk artikel. Kenyataan untuk menulis artikel cukup sulit tidak hanya dialami oleh orang awam tetapi dialami juga oleh siswa. Dalam sebuah jurnal berjudul "Using Agile Development Methods To Improve Student Writing", yang disusun oleh Clifton Kussmaul dari Mathematical Sciences
Department Muhlenberg College Allentown, 2004 memaparkan bahwa banyak orang baik di dalam maupun di luar akademisi setuju bahwa perlu membantu meningkatkan keterampilan Siswa dalam menulis dan komunikasi lainnya. Selain membuat siswa lebih diberdayakan, menulis dapat membantu mereka memahami konsep yang sulit.

\section{TINJAUAN PUSTAKA}

Menurut Bodnar dan Hopwood (1995) dalam Nasution (2004) ada tiga komponen utama yang berkaitan dengan penerapan TI berbasis komputer yaitu:

a. Perangkat keras (hardware).

b. Perangkat lunak (software).

c. Pengguna (brainware).

Ketiga elemen tersebut saling berinteraksi dan dihubungkan dengan suatu perangkat masukan keluaran (input-output media), yang sesuai dengan fungsinya masing-masing. Perangkat keras (Hardware) adalah media yang digunakan untuk memproses informasi Perangkat lunak (software) yaitu sistem dan aplikasi yang digunakan untuk memproses masukan (input) untuk menjadi informasi, sedangkan pengguna (brainware) merupakan hal yang terpenting karena fungsinya sebagai, pengembang hardware dan software, serta sebagai pelaksanaan (operator) masukan (input) dan sekaligus penerima keluaran (output) sebagai pengguna sistem (user). Pengguna sistem adalah manusia (man) yang secara psikologi memiliki suatu prilaku (behavior) tertentu yang melekat pada dirinya, sehingga aspek keprilakuan dalam konteks manusia sebagai pengguna (brainware) TI menjadi penting sebagai faktor penentu pada setiap orang yang menjalankan TI.

Pada penelitian dengan judul "Computer-based concept mapping tools in business" yangdilakukan oleh Louis C $\mathrm{H}$ 
Fourie pada University of Stellenbosch, diuraikan bahwa knowledge adalah salah satu sumber daya yang paling penting bagi suatu organisasi untuk mencapai keuntungan kompetitif. Sayangnya implementasi sistem manajemen pengetahuan yang telah ada, sering gagal sebagian disebabkan oleh metode menangkap dan mem-presentasikan pengetahuan (Fourie, 2004,p2).

Sejak tahun 1990-an banyak organisasi telah mulai fokus pada knowledgemanagement dengan tujuan untuk memanfaatkan lebih efektif knowledge sebagai aset organisasi. Sehingga organisasi melakukan investasi uang dalam jumlah besar untuk pengembangan dan pelaksanaan sistem knowledgemanagement yang efektif agar dapat menangkap, mengelola, dan menyebarkan knowledge (McCune, 1999:p2). Persentase yang tinggi dari implementasi ini telah gagal (Van Buren, 1999:p2) dan seringkali tidak memberi kontribusi pada keuntungan kompetitif. Kurangnya keberhasilan kebanyakan disebabkan antara lain dengan metode meng-captureknowledge dan memahami knowledge. Keengganan untuk menulis knowledge dalam bentuk artikel dan kesulitan memahami tulisan dalam bentuk artikel dari sisi penerima.

Kebanyakan bahasa yang digunakan untuk merepresentasikan knowledge, dan hasil pemikiran di dalam bentuk format teks murni. Namun, representasi tekstual merupakan bentuk yang tidak mudah dimengerti, khususnya bagi orang-orang yang tidak biasa membaca teks. Representasiknowledge dalam bentuk visual bergantung pada grafis daripada teks. Representasi visual yang lebih dimengerti dan transparan daripada pernyataan tekstual.

Penelitian lain yang dilakukan oleh oleh Bo Hansen Hansen, Karlheinz Kautz, Department of Informatics, Copenhagen Business School Howitzvej 60 6., DK-2000 Frederiksberg, Denmarkberjudul
"Knowledge Mapping: A technique for identifying knowledge flows in organizations", dijelaskan bahwa sebuah organisasi modern termasuk perusahaan pengembangan perangkat lunak, pengetahuan merupakan parameter kunci untuk dapat bertahan dalam persaingan, karena kemampuan untuk terus produksi menjadi lebih baik di layanan bergantung pada praktek kemampuan untuk menggabungkan pengalaman sebelumnya dalam perencanaan masa depan. Kemampuan ini sangat tergantung pada kemampuan organisasi untuk berbagi knowledge dan dengan demikian mampu menciptakan jalur agar knowledge dapat mengalir pada organisasi. Dalam karya ini penulis memberikan perspektif pengetahuan pada manajemen yang menjelaskan bagaimana menggunakan gambar sebagai sebuah kaya teknik untuk pemetaan knowledge dalam organisasi.

Mapping sendiri juga dapat berfungsi sebagai alat komunikasi yang penting, karena penggunaan gambar sebagai teknik analisis untuk mappingknowledge sehingga dapat mengalir dalam suatu organisasi. Teknik mapping memiliki kemampuan untuk mempermudah mendapatkan sebuah pemahaman untuk memberikan gambaran secara menyeluruh, mudah dimengerti, dan alat komunikasi visual (Bo Hansen Hansen, 2000:p1-3).

\section{METODE PENELITIAN}

Dalam pembuatan suatu program aplikasi dibutuhkan adanya suatu analisis yang tepat tentang hal-hal yang dibutuhkan, setelah sebelumnya dilakukan proses perencanaan sehingga didapat suatu program aplikasi yang sesuai dengan kebutuhan. Setelah proses analisis dilakukan dengan benar, maka dapat diketahui kebutuhan sistem dengan tepat. 
Dalam penelitian ini, pendekatan yang dilakukan untuk aktifitas berbagi pengetahuan di balai Teknologi dan Komunikas adalah Pusat Sumber Belajar (PSB).

Adapun spesifikasi rancangan sistem yang akan dibangun dapat dijelaskan sebagai berikut.

a. Sistem yang akan di bangun adalah Pusat Sumber Belajar (PSB).

b. Kemampuan sistem secara umum adalah untuk proses berbagi pengetahuan antar guru di provinsi Banten serta mengcapturetacit knowledge sehingga menjadi explicit knowledge.

c. Pusat Sumber Belajar (PSB) ini berbasis web sehingga harapannya dapat diimplementasikan dalam jangkauan yang lebih luas. Hal ini sebagai antisipasi apabila perkembangan jumlah guru yang terlibat semakin luas.

d. DBMS dirancang dengan menggunakan software MySQL dengan nama database Knowmap, terdiri dari tabel master Guru, topik, divisi, dan tabel transaksi terdiri dari login, content dan comment.

e. Pemakai sistem adalah guru-guru di Provinsi Banten yang sudah terdaftar dalam database dengan identitas userid dan password sebagai hak akses.

f. Untuk melakukan akses terhadap system, setiap user wajib mengisi form login dengan memasukan userid berupa alamat e-mail dan password.

g. Apabila user memiliki hak akases maka akan ditampilkan menu utama / home yang terbagi menjadi bagian kepala yang diisi dengan baner (judul), dan badan yang dibagi menjadi dua bagian yaitu panel dan content. Panel akan berisi menu yang dapat dioperasikan. Content adalah tempat untuk menampilkan informasi yang diakses.

h. Menu utama terdiri dari beberapa bagian yaitu:
1. Menu bar berisi daftar Materi yang sudah dimasukan, mencari judul Materi yang diinginkan dan fasilitas untuk menambah Materi baru. User yang memiliki hak akses pada menu ini dapat memberi komentar dari isi Materi.

2. Menu profil sekolah berisi data sekolah asal guru

3. Menu agenda digunakan untuk menambah kegiatan penulis, yang berfungsi untuk berbagi knowledge.

4. Menu link terkait berfungsi untuk menghubungkan dengan website yang berhubungan dengan Pusat Sumber Belajar (PSB).

5. Statistik User berfungsi untuk mengetahui berapa banyak user yang memanfaatkan website ini sebagai sarana Pusat Sumber Belajar (PSB)

i. Master data hanya dapat dioperasikan oleh administrator yang memiliki hak akses untuk menambah, mengubah atau menghapus data-data master seperti data guru, user, dan topik.

j. Proses upload content knowledge dilakukan pada form yang tersedia dengan cara memilih topik dari daftar yang sudah dimasukan, memasukan judul, memberikan deskripsi atau penjelasan singkat tentang isi knowledge serta menyajikan knowledge. User yang melakukan proses ini dinamakan knowledge provider.

k. Sementara guru lain bertindak sebagai knowledge receiver dapat mencari dan membaca informasi yang dibutuhkan dengan menggunakan fasilitas pencarian dan memasukan judul sebagai kata kunci content yang akan dicari. Setelah ditampilkan beberapa judul yang sesuai dengan hasil pencarian selanjutnya dapat meng-klik pada salah satu judul yang tersedia dan akan ditampilkan informasi secara lengkap. Bila menghendaki 
knowledge receiver dapat memberikan tanggapan terhadap isi materi dalam knowledge tersebut.

\section{HASIL DAN PEMBAHASAN}

Hasil perancangan selanjutnya diimplementasikan dalam program dengan nama Pusat Sumber Belajar atau PSB, menggunakan bahasa php untuk medesain dan fungsi tampilan, serta MySQL sebagai DBMSnya

Dalam penyusunan Pusat Sumber Belajar (PSB) berbasis web Semantic ini penyimpanan data di implementasikan menggunakan Database Management System (DBMS) MySqlyang dibuat dan diberi nama "dbpsb". Tabel Topik digunakan untuk menyimpan master data topik, terdiri dari dua field yaitu topikid dan topik dengan topikid sebagai primary key.

Tabel Content digunakan untuk menyimpan data materi berbasis web Semantic yang terdiri dari field : contentid, nik, topikid, judul, deskripsi, mindmap dan tanggal dengan contentid sebagai primary key.

Tabel guru digunakan untuk merekam master data profil guru sebagaiknowledge provider atau knowledge receiver. Tabel ini terdiri dari beberapa field yaitu nik, nama, tmplhr, tgllahir, tglmasuk, alamat, agama, sex, divisi, pekerjaan, email, password, foto dan jenis dengan nik sebagai primary key.

Tabel Sekolah digunakan untuk menyimpan master data sekolah. Terdiri dari field divisiid dan divisi dengan divisiid sebagai primary key.

Implementasi, Pada Menu utama ada pilihan Registrasi Guru dan Login Guru, bagi yang belum terdaftar sebagai guru maka harus melakukan registrasi guru dan untuk yang sudah punya login guru maka dia harus plih Login Guru

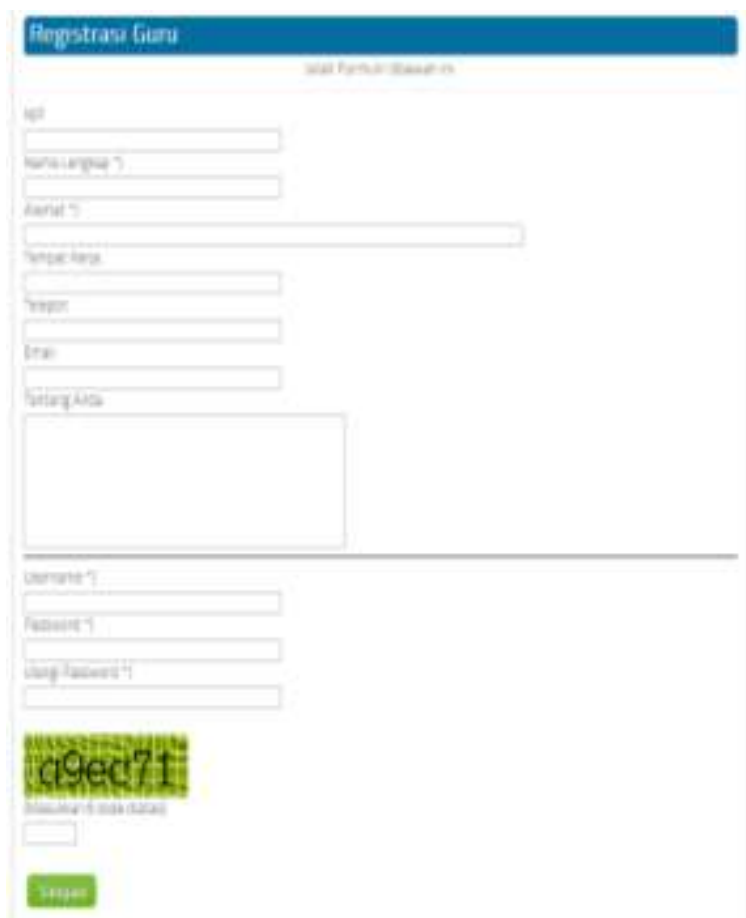

login Guru : yaitu untuk login masingmasing guru dengan mengisikan username dan passwordnya

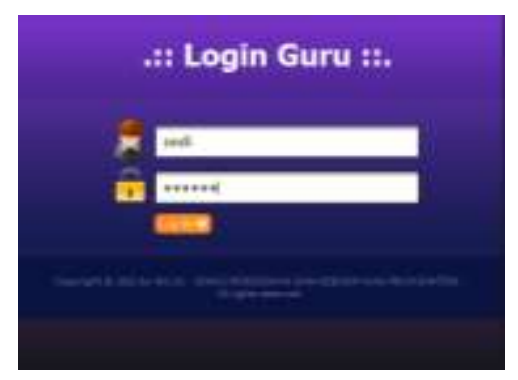

Masukkan Username dan Password, kemudian klik Login. Jika kombinasi username, password, maka sistem akan menampilkan halaman utama Modul Guru 


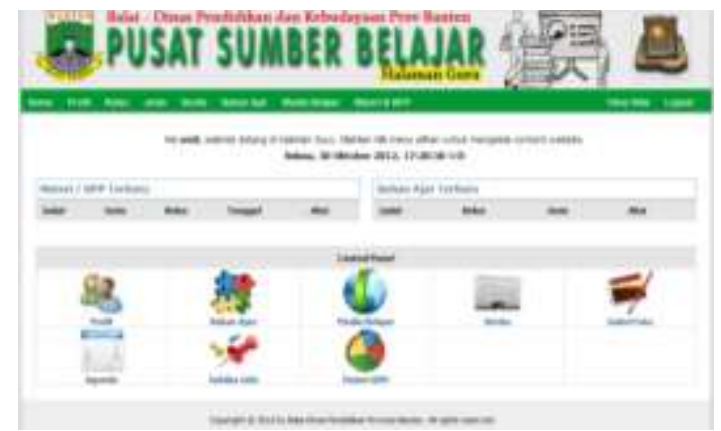

Modul Guru yaitu modul yang terdiri dari menu Home, Profil, Kelas, Jenis , Berita, Bahan Ajar, Media Belajar, Materi RPP, Agenda, Sekilas Info, Galeri Foto, View Web dan Logout

Pengujian Aplikasi, Aplikasi Pusat Sumber Belajar (PSB) yang telah dibuat, selanjutnya diuji melalui teknik pengujian perangkat lunak yang meliputi pengujian white box dan black box.

Metode white box ini adalah suatu metode desain test case yang menggunakan struktur kontrol desain prosedural untuk memperoleh test case. Dengan menggunakan metode pengujian white box, perekayasaan sistem dapat melakukan test case yang dapat :

a. Memberikan jaminan bahwa semua jalur independen pada suatu modul telah digunakan paling tidak satu kali.

b. Menggunakan semua keputusan logis pada sisi true dan false.

c. Mengeksekusi semua loop (perulangan) pada batasan mereka dan pada batas operasional mereka

Pengujian selanjutnya dilakukan untuk memastikan bahwa suatu event atau masukan akan menjalankan proses yang tepat dan menghasilkan output sesuai dengan rancangan.

Untuk mengukur efektifitas dari implemnetasi Pusat Sumber Belajar (PSB), dibuat dua kuisiner yang berikan kepada beberapa orang guru yang dipilih secara acak. Kuisioner yang pertama untuk menggali data awal tentang hal-hal yang berhubungan dengan proses berbagi pengetahuan diperusahaan. Dan kuisioner kedua untuk mengukur kondisi awal sebelum implementasi Pusat Sumber Belajar (PSB) berbasis web Semantic dan setelah diimplementasikannya Pusat Sumber Belajar (PSB).

\section{KESIMPULAN}

Dari hasil penelitian yang dilakukan mulai dari tahap awal hingga proses pengujian dan pengukuran, dapat disimpulkan bahwa dengan diimplementasikannya Web Semantic pada Pusat Sumber Belajar di Balai Teknologi dan Komunikasi Dinas Pendidikan Provinsi Banten maka E-Learning dapat digunakan untuk Sharing Knowledge pada Balai Teknologi dan Komunikasi Provinsi Banten dengan cara :

a. Melakukan analisa kebutuhan pemakai

b. Membangun database

c. Mengimplementasi program menggunakan programming Joomla

d. Melakukan Black Box Testing

\section{DAFTAR PUSTAKA}

Bo Hansen Hansen, K. K. Knowledge Mapping: A technique for identifying knowledge flows in organisations. Department of Informatics, Copenhagen Business School , 1-3., 2000.

Buzan, T. Buku Pintar Mind Map. Jakarta: Gramedia Pustaka Utama, 2007

Buzan, T. Mind Maps at Work. Jakarta: Gramedia Pustaka Utama, 2007 
Buzan, T. Use your Perfect Memory teknik Optimalisasi daya ingat. Yogyakarta: Icon Teralintera, 2002.

Fourie, L. C. Computer-based concept mapping tools in business. University of Stellenbosch , 2-4, 2004.

Igarashi, T. N. An Application-Independent System for Visualizing User Operation History. Department of Computer Science The University of Tokyo , 23-24, 2008.

Johansson, J. B. The Students Conference-A Tool for the Teaching of Research, Writing, and Presentation Skills. Department of Computing Science , 28-29, 1998

Khairul Muluk, M. D. Knowledge Management Kunci Sukses Inovasi Pemerintah Daerah. Surabaya: Bayu Media \& Lembaga Penerbitan Unibraw, 2008.

Kussmaul, C. Using Agile Development Methods To Improve Student Writing. Mathematical Sciences Department Muhlenberg College , 149-150, 2004

Sangkala. Knowledge Management. Jakarta: Raja Grafindo Persada, 2007

Wahono, R. S. Knowledge Management dan Dunia Pendidikan:Studi kasus IlmuKomputer.com. Unpad Bandung, 2, 2006 